\title{
Perception and acceptance of rooftop farming by residents in Bangalore, India
}

\author{
Prof. Shruti M Aiholli and Ms. Tadi Bindu Bargavi \\ Faculty of Architecture, Manipal Academy of Higher Education, \\ Academic block 2, MIT Campus, Manipal, Udupi District, Karnataka, India
}

\begin{abstract}
Urbanization is making urban communities grow and increase in density. As this occurs, nature is expelled from urban areas and use of solid, slate and metal surfaces; carbon discharges increase the Urban Heat Island Effect. Rooftops are the spots that give an individual a chance to fantasize and allow them an imaginative standpoint towards their environment. What better place could there be for a garden or far and away superior, a vegetable garden? Rooftops are underutilized whereas it has a great potential. This paper is the study to understand the scope of development and perception of rooftop farming in residences in Bangalore. Two distinct surveys have been conducted to know the citizen's perception of the rooftop farming: one being a practitioner survey and the other is the non-practitioner survey. Rooftop farming has a wide applicability in zones with moderate climate and hence could be incorporated in the city very efficiently. To conclude, a few guidelines have been recommended to enhance rooftop cultivating practice and urge more individuals to rehearse rooftop farming for the better change of urban life.
\end{abstract}

Key words: Environmental benefits, Food production, rooftop farming, urban agriculture.

\section{INTRODUCTION}

The rapid urbanization is a critical factor in modifying city's spatial structure and influencing the biology and condition. As mentioned in the data booklet 'The world's Cities in 2016' - About 54 per cent of the World's population lives in urban areas. The United Nation forecasted that more than 70 per cent of the world's population will be living in cities by 2050 . Bangalore, the metropolitan city in India is also urbanizing rapidly. In this process of urbanization, the city is losing the green spaces. In one of the interview, IISc Professor Ramachandra told that the city has already lost " 88 per cent of green cover and 79 per cent of lakes and waters bodies". Which means the city is more prone to the phenomenon called "urban heat island'. As stated by author Kheir Al-Kodmany -"cities all over the world are grossly unprepared for embracing vertical density, because it may aggravate multidimensional sustainability challenges resulting in a 'vertical sprawl' that could have worse consequences than 'horizontal' sprawl'[1]. The intensity of urban growth is uncontrollable and it is effecting massive demand on food supply system. Roof top farming offers many social, economical and environmental benefits to the high density cities like Bangalore. Because it supports the local food production, reduces the transportation energy and cost, reduces the air pollution, improves the personal and public health and also enhances the community development.

In Bangalore, open and green spaces are converted to built-up spaces and thus there is no scope for cultivation on ground. Implementing the rooftop farming is the best solution to make self-sufficient and access fresh food items to residents, reduces noise levels, reduces $\mathrm{CO}_{2}$ in the atmosphere, cooling the microclimate, reduces food mile, increases the biodiversity and provide space for birds and insects.

This study aims at the study of rooftop farming practices and related rooftop farming challenges faced by the Bangalore residents. By identifying the perspective of the residents through survey, it gives clear understanding of the scope of rooftop in Bangalore.

\section{URBAN SUSTAINABILITY AND ROOFTOP FARMING}

The community plays important role in addressing the issue of city sustainability. The purpose of the sustainable city should be at least to create its own ecological balance without expecting renewable energy from the country side. It should have the control on the 
pollution, usage of land, transportation issues and the material usage. Along with the government and other private organizations schemes, rooftop farming is possible by the residents of metropolitan cities.

Social sustainability is possible by the active community participation while sharing the common ideas towards collecting fresh food items from rooftop farming. It is also beneficial for the amenity space for recreation and everyday exercise routine. It adds to the aesthetic value of the building. It can be benefited to the local employment and educate the interested citizens.

Economic sustainability is possible by implementing rooftop farming while producing local food items for sale which increases the food security. It increases the local food security, reduces the building energy costs and increase the roof life span.

Environmental sustainability is possible by implementing rooftop farming which generates very less food packaging system, improves environmental air quality and also reduces the noise levels. It reduces the transportation cost and energy, mitigate the urban heat island effect, recycle the organic waste by composting, improves the storm water and increase the biodiversity.

\section{TYPES OF ROOFTOP FARMING}

Rooftop farming can be implemented in residences in three ways. The very first one is gardening in containers called container gardening. The second type is green roof and the third type is hydroponic rooftop farming.

\section{Container gardening}

Container farming enables you to develop edibles in the smallest of spaces. The least demanding and closest to the home way is the utilization of containers. You can make any style of the rooftop cultivate with container developed plants. Containers are ideal for rooftop farming since they are light, versatile, adaptable and reasonable. Container farming has numerous utilization; it is an exceedingly adaptable type of planting that is particularly compelling for urban settings since it stays away from issues out of reach or faulty soil.

These non-conventional gardens do not expect access to the ground; they just need an empty space, on any sort of surface, Containers can be made with the sorts of materials that are accessible anyplace - like plastic pails, pieces of wood, old delivery boxes, or huge sacks, container cultivating, whenever permitted, is a brilliant choice for some non-business urban rooftop gardens, especially for individuals who do not have the methods or the will to roll out improvements to the real structure of the roof.

\section{Maintenance}

Planters may favor earthenware pots to plastic, metal, or wood, for instance, earthenware frequently breaks amid overwhelming downpours during winter and should be brought inside on the off chance that it is to be secured. Since earthenware is permeable, earthenware pots additionally lose dampness too effortlessly, which is the issue on rooftops, where the brutal condition manages that plant specialists utilize containers which hold dampness. Wood, plastic, or metal containers, by and large, survive the winter better and hold soil dampness great.

\section{GREEN ROOFS}

Green roofs are fancier and costlier when contrasted with rooftop container farming. Costs fluctuate as indicated by the sort of framework utilized. Every single green roof has an arrangement of advantages in like manner however differ in their different properties. There are two types of green roofs intensive and extensive green roofing. As stated by the author Waichin $\mathrm{Li}$, - "Extensive green roofs are often the target of scientific research since it costs less than intensive green roof" [2].

Green roof system consists of growing medium and the drainage system that reduces the water retention. Author Waichin Li, states that - "scopes of green roof studies are including the temperature reduction caused by green roofs, runoff quantity control as well as reduction of pollution" [2]. He also mentions that - "From soil formation on green roofs, it improves the urban biodiversity, for underground animals in the growth substrate, for the inserts in the canopy" [2].

\section{Benefits}

Green roofs have excellent noise attenuation, especially for low frequency sounds. It has been noted that "an extensive green roof can reduce sound from outside by 40 decibels, while an intensive green roof can reduce sound by 46-50 decibels". Author Waichin Li stated that - "green roofs are good for rebuilding green areas in urban area; however, it should not be an excuse to destroy the outskirt green belts as green roofs cannot replace the role of natural habitat. Aesthetic Improvements, local job creation and many more benefits" [2].

\section{HYDROPONICS}

Hydroponics is a technique for developing plants without soil. The most perfect type of hydroponics is water culture, in which a plant's crown is upheld by a thin layer of the substrate, while its foundations are submerged in a supplement arrangement. Although it is a framework frequently disregarded in talks of roof gardens, Hydroponics is a technique appropriate to rooftops, since the containers utilized in hydroponics 
can be lighter-weight than soil-filled containers, and since hydroponics frameworks can be very versatile. Plants require light, supplements, carbon dioxide, water, warm, and natural air.

\section{Benefits}

Plants grows quicker since they have prepared access to supplements and water, and put their vitality into developing leaves, natural products, and stems, rather than roots. As stated by author W. H. Schnitzler, "Rooftops planted with vegetables are 7 degree cooler than those next door - and when practiced on green belt, improves landscape and citizens' quality of life"[3]. Numerous hydroponic frameworks are mechanized and don't require work, and pesticides are occasionally vital because plants begin on a medium that is sans illness.

\section{CONSIDERATIONS BEFORE SETTING UP A ROOFTOP FARM}

There are few peculiarities to consider while setting the rooftop farming.

Consent: One should be interested to cultivate and maintain on everyday basis which is critical and responsible job. It is not beneficial to oneself, but also to the surrounding environment. Author Neda Jafari stated that - "Rooftop agriculture allows for the retention of traditional or cultural gardening practices while local choice of plants can preserve heritage species and maintain diversity in the diet" [4].

Structural Integrity: Density of soil and other components of rooftop farming will effect on the weight of the structure. Special considerations should be encountered during the structural details. Water proofing is essential as a part of design strategy which reduces the intensity of seepage of water. Author Sam C. M. Hui states that "Retrofitting an existing roof may not be feasible if the structural capacity of the roof is not adequate" [5].

Water: Watering the plants everyday basis is essential, so providing the extra supply to the terrace would help the gardener to maintain the farming. Water requirement for each plant container should be guided to the gardener. Designing drip irrigation system would help few local plants to grow healthy and fast. Leakage and wastage of water should be considered as the critical issue and need to be addressed.

Sun Exposure: Few local plants fro in shaded area, but some plants need sun exposure. So if the plants are shaded by the surrounding buildings, there should be replaced in the sunny area for the better quality. Author Sam C. M. Hui states that "Although there are some difficulties such as moving the vegetation, finding the access to roof areas, or maintaining vegetation on the roof, the all-day exposure to sunlight is suitable for vegetable growing" [5].
Wind: Wind has the capacity to bring down the grown plants. So providing fencing or the divider to protect from the local winds would help to maintain the quality of the plants. In that case, it is suggested to look into the local building codes for height restrictions. This would also give security from birds and monkeys.

Capacity: Space being the main requirement of rooftop farming, it is advised to utilize the area efficiently. Author Neda Jafari stated that - "Value of roof space as a way of increasing densities by integrating uses which normally occupy extensive sites at ground level has long been recognized" [4].

\section{CASE STUDY OF TWO GARDERNERS IN BANGALORE}

A case study is done on rooftop farming in residential building of Bangalore city and the inferences are compared with the analysis of surveys.

A case study is conducted at a rooftop farming practitioner Ms. Preethi's house in Bangalore city. She practicing rooftop farming from past 5 years. She started growing in containers and grow around 7 types of vegetables - onions, tomatoes, lettuce, mint, garlic, ginger, potatoes, cauliflower, cabbage, eggplant, Spinach and fenugreek. She also grows herbs and flowers to provide aesthetical appearance to her rooftop. She says that the products obtained are enough for her 4 family members and she doesn't sell any of them. She spends about 500 Indian rupees a month for growing and maintaining of these vegetables. She approached their neighbors and guided them to invest on the roof top farming. But very few followed the instructions and they do share ideas about the development of the rooftop farming. Author Sam C. M. Hui states that "if the farming can recruit workers and volunteers at the neighbourhoods, this can help promote local employment and re-engage the community to participate and be part of the urban harvest" [5].

Another case study is conducted at the rooftop farming practitioner Ms. Katherene Deborah, in Bangalore. She started with rooftop farming from 2010. She also practices container gardening on her house terrace. She grows lettuce, spinach, tomatoes, onions, chilly, ginger, garlic, sweet potatoes, eggplant, fenugreek, beans, guavas, fig, lemons, radishes, ladies finger, carrot, oranges, custard apples, beetroot and lot of herbs. She uses the products/items for her family use only. She invested 2000 Indian rupees in the initial installment. She spends only on neem oil as pesticides. The veggies produced are fresh and healthy as she uses the organic waste produced in her kitchen as compost fertilizer.

Both of them have used the drums, plastic tub for cultivating the plants of vegetables and fruits. Both of 
them have not hired gardener for the maintenance. Both of them maintain their garden by their own.

It can be inferred that by having a rooftop farming, there will be reduction in the usage of market products which are usually not fresh and we can also see reduction in number of travel to market to get vegetables. The veggies produced are fresh and healthy as she uses the organic waste produced in her kitchen as manure and not pesticides. Author Sam C. M. Hui states that "Rooftop vegetable garden is a strategy for intensifying urban agriculture activities, which can improve nutrition and food security in urban neighbourhoods while reducing dependence on an energy-intensive global food economy" [5].

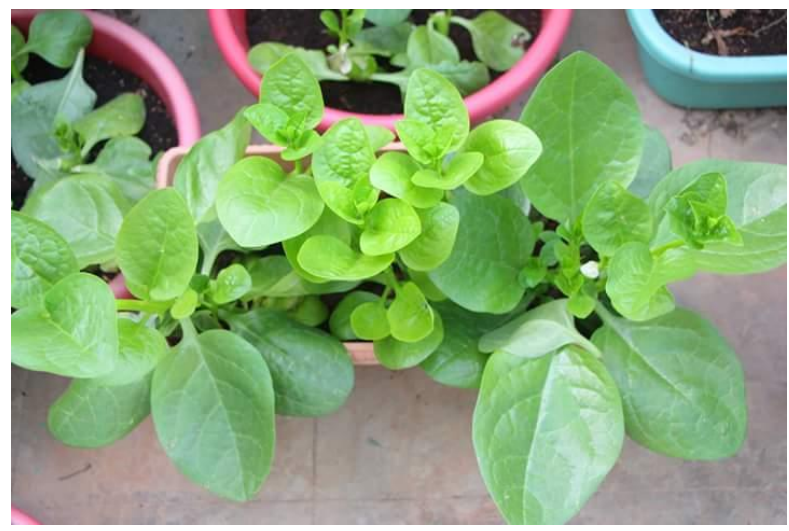

Fig 1 Overview of the roof garden in Bangalore
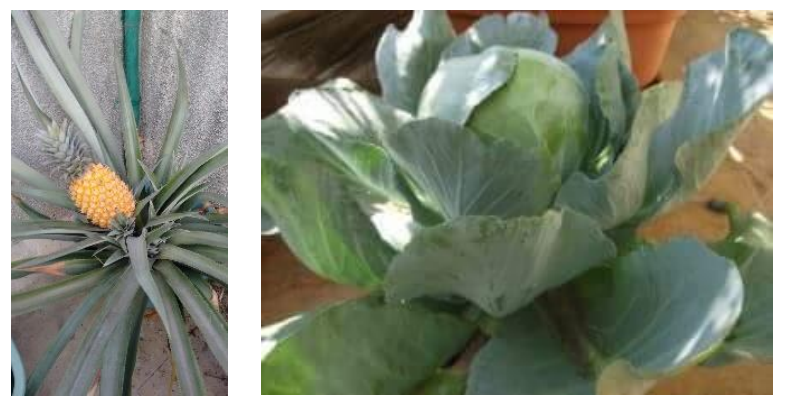

Fig 2 Overview of grown fruit and vegetable on rooftop of Bangalore

\section{PRACTITIONER SURVEY OBSERVATIONS}

1) $69 \%$ of the practitioners are using container farming, 30\% are using green roof farming, and very few are practicing hydroponics and Aeroponics. This is clear to understand that there is no awareness of hydroponics and aeroponics in Bangalore city.

2) $87.2 \%$ of the practitioners are using natural alternatives for pest control which shows the interest of natural measures taken by residents of Bangalore.

3) $61.5 \%$ of the practitioners appointed gardener to maintain the rooftop farming. Few of them dropped the rooftop farming because they could not maintain it and they did not spend time on maintenance.
4) As shown in the figure $3,74.4 \%$ of the residences have seating arrangement along with the rooftop farming, $41 \%$ have the play area, $30.8 \%$ have storage area and $2.6 \%$ have the study area along with the rooftop farming.

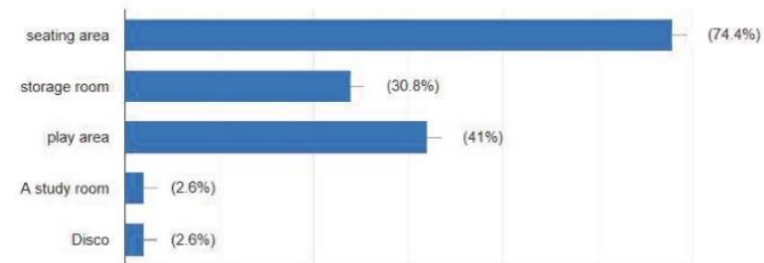

Fig 3 Graph showing the activities happening on rooftop along with farming. Field survey 2018

5) $80 \%$ of the practitioners believe that there is less awareness about the rooftop farming in the Bangalore city.

\section{CHALLENGES FACED BY PRACTITIONER IN BANGALORE}

There is no major issues like high rainfall and high winds in Bangalore city. But the residents do not have much experience and hence loose interest in maintaining the rooftop farming. Without proper guidance or training, maintenance of roof top farming becomes difficult and hence residents get frustrated which results in unwilling on such new initiatives. Due to droppings of leaves, cleaning the roof top regularly becomes the tedious job for the residents.

Rooftop farming is effected by the encroachment of monkeys sometimes, sometimes by birds which spoils the vegetables and fruits.

Challenges faced by the residents staying in the apartments of Bangalore, would get only small portion of the balcony for gardening purposes. Few residents are staying on rent basis, which is the critical response towards gardening because the owner restricts them to develop rooftop farming.

Old structures cannot bear the soil density and hence load bearing capacity is one of the major concern towards the rooftop farming. But there are possibilities like hydroponics and aeroponics techniques that can be implemented in such cases. As discussed earlier, the awareness of hydroponics and aeroponics is literally zero and neglected.

New residences which are capable of rooftop farming need to consider the quality of soil and depending on the rainfall intensity, depth of the soil should be calculated.

\section{NON- PRACTITIONER SURVEY OBSERVATIONS}

From these graphs we can infer that there is lack of awareness among the people about rooftop farming which actually has a great potential in having a healthy life. 
1) As shown in the figure $4,74.2 \%$ of the residents have flat roof where there is high possibility of rooftop farming.

Fig 4 Graph showing the type of roof of non-practitioner
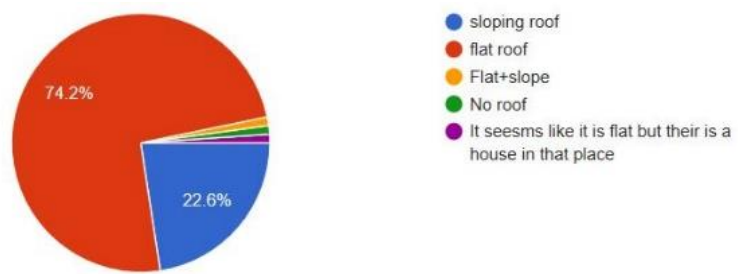

residents in Bangalore. Field survey 2018

2) As shown in the figure $5,31.2 \%$ of the residents are known to rooftop farming, 57\% of the residents have very less knowledge about rooftop farming and $11.8 \%$ haven't heard about the rooftop farming.

Fig 5 Graph showing the percentage of awareness of rooftop

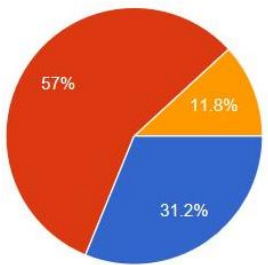

yes,i am aware of it

heard about it but dont know exactly

dont know anything about this

farming among the non-practitioners in Bangalore. Field survey 2018

3) As shown in the figure $6,34.8 \%$ residents recycle produce homebased waste which can be enhanced and utilized for rooftop farming.

Fig 6 Graph showing the percentage of recycling the

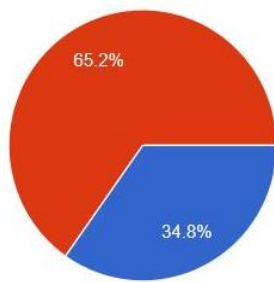

Yes

homebased waste for roof rooftop farming. Field survey 2018

4) As shown in the figure 7, only $36.6 \%$ residents showed $100 \%$ interest towards rooftop farming and $58.1 \%$ are not sure that they can maintain it and remaining are not willing to spend time on farming.

Fig 7 Graph showing the percentage of residents willingness

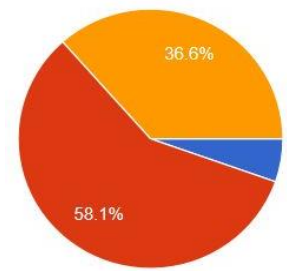

not at all willing to

may practice in future

definately yes

towards rooftop farming in Bangalore. Field survey 2018

\section{CHALLENGES FACED BY NON- PRACTITIONER IN BANGALORE}

While surveying the non-practitioners, it is been observed that people do not have leisure time to take care of the roof garden. Most of them are busy with the official works and don not have time to spend on the roof garden.

Another challenging is lack of knowledge on roof top garden who are seeking help from neighbors, government and other private organizations for installation method and maintenance issues. Author Sam C. M. Hui states that "it is important that urban farmers receive incentives from growing food because the urban agriculture provides not only local fresh food for the city, but also reduces the cost of food transportation" [5].

Few of them are happy to buy products from the super market instead of growing them on their terrace, because time, labour and money as a constraint.

Most of the houses terrace are occupied by other activities, so area requirement for rooftop farming is restricted. Very few replied that they are not interested to develop roof top garden.

\section{RECOMMENDATIONS}

The people of Bangalore city are not are of such roof top farming benefits towards social, economical and environment. Because, there are no efforts from the government to reach out the public to improve on the city sustainability. Through the support of NGO's, government should initiate the programmes which is beneficiated to city and also public health.

Government should also make mandatory for residence construction and should give bonus FAR for those who implement the rooftop farming. This will increase in the number of residents taking charge of joining hands towards sustainable city.

Recommending about the rooftop farming to builders will enhance the economical benefits and also help residents to take care of their fresh foods. Making some modifications in the construction by providing extra water tap, extra structural support, designated area for rooftop garden would help interested practitioners to help in changing the microclimate.

Government initiative towards encouraging builders with some incentives would help in building a sustainable city.

Government should take the help from the stakeholders who are responsible of marketing about the rooftop farming techniques. This would help their business and also residents to implement rooftop farming easily without difficulty. In order to increase the intensity of 
the information on benefits, costs and technology involved in roof op farming, government should utilize the strategies to contact policy makers, architects, Building developers, interested citizen of the city.

\section{CONCLUSION}

As the population and pollution is increasing in Bangalore metro city, expenditure on food and transport is also increasing. Since the resource is transported from the surrounding villages, there is a high usage of energy involved. There is also scarcity of land in the city which indicates that it is high time for individuals to make usage of their rooftop for farming. Rooftop farming will help them to utilize fresh food items without investing on travel time and money. It also contributes towards sustainability city which ensures urban greenery.

But the government initiatives plays an important role in mitigating climate change and support environmental friendly techniques like rooftop farming. If government initiate concentrating on rooftop farming incentives, all the incentives, the builders and the stakeholders would join hands to develop a sustainable city.

\section{REFERENCES}

[1] Kheir Al-Kodmany. 2018. The Vertical Farm: A Review of Developments and Implications for the Vertical City. MDPI, Basel, Switzerland.

[2] Waichin Li., K. K A Yeung. 2014. A comprehensive study of green roof performance from environmental perspective. Elsevier B.V.

[3] W. H. Schnitzler. 2012. Urban Hydroponics for green and clean cities and for food security. ISHS Acta Horticulture1004.

[4] Neda Jafari., Nangkula Utaberta., Mohd Yazid Mohd YUNOS., Nor Atiah Ismail., Sumarni Ismail., Noor Fazamimah Mohd Ariffin., Nastaran Jafari., Mahkameh Valikhani,. 2015. Benefits of Roof garden in order to usage of Urban Agriculture at Roof Garden in High-Rise Building in Malyaisa. AENSI

[5] Dr. Sam C. M. Hui. 2011. Green roof urban farming for buildings in high-density urban cities. ResearchGate 